\title{
Subtypes of borderline personality disorder patients: a cluster-analytic approach
}

\author{
Maaike L. Smits ${ }^{1 *}$, Dine J. Feenstra ${ }^{1}$, Dawn L. Bales ${ }^{1,2}$, Jasmijn de Vos ${ }^{3}$, Zwaan Lucas $^{4}$, Roel Verheul ${ }^{1,5}$ \\ and Patrick Luyten ${ }^{6,7}$
}

\begin{abstract}
Background: The borderline personality disorder (BPD) population is notably heterogeneous, and this has potentially important implications for intervention. Identifying distinct subtypes of patients may represent a first step in identifying which treatments work best for which individuals.

Methods: A cluster-analysis on dimensional personality disorder (PD) features, as assessed with the SCID-II, was performed on a sample of carefully screened BPD patients $(N=187)$ referred for mentalization-based treatment. The optimal cluster solution was determined using multiple indices of fit. The validity of the clusters was explored by investigating their relationship with borderline pathology, symptom severity, interpersonal problems, quality of life, personality functioning, attachment, and trauma history, in addition to demographic and clinical features.

Results: A three-cluster solution was retained, which identified three clusters of BPD patients with distinct profiles. The largest cluster ( $n=145$ ) consisted of patients characterized by "core BPD" features, without marked elevations on other PD dimensions. A second "Extravert/externalizing" cluster of patients $(n=27)$ was characterized by high levels of histrionic, narcissistic, and antisocial features. A third, smaller "Schizotypal/paranoid" cluster $(n=15)$ consisted of patients with marked schizotypal and paranoid features. Patients in these clusters showed theoretically meaningful differences in terms of demographic and clinical features.
\end{abstract}

Conclusions: Three meaningful subtypes of BPD patients were identified with distinct profiles. Differences were small, even when controlling for severity of PD pathology, suggesting a strong common factor underlying BPD. These results may represent a stepping stone toward research with larger samples aimed at replicating the findings and investigating differential trajectories of change, treatment outcomes, and treatment approaches for these subtypes.

Trial registration: The study was retrospectively registered 16 April 2010 in the Nederlands Trial Register, no. NTR2292.

Keywords: Borderline personality disorder, Cluster analysis, Subtypes, Comorbidity, Personality dimensions

\section{Background}

Borderline personality disorder (BPD) is among the most prevalent personality disorders [1]. BPD is associated with a high disease burden in terms of high levels of psychiatric comorbidity, low quality of life, high levels of acting out, and a high lifetime risk of completed suicide, as well as high societal costs [2].

The BPD population is notably heterogeneous from a descriptive and theoretical perspective. Two hundred fifty-six possible combinations of criteria may yield the

\footnotetext{
*Correspondence: maaike.smits@deviersprong.nl

'Viersprong Institute for Studies on Personality Disorders, Halsteren, The Netherlands

Full list of author information is available at the end of the article
}

same diagnosis. Hence, two patients with a diagnosis of BPD may have only one diagnostic criterion in common [3]. Moreover, the high prevalence of comorbid pathology amongst patients with BPD is widely recognized [4]. Therefore, large variation in expression of BPD pathology is apparent in clinical practice. Heterogeneity in the BPD population poses challenges in clinical practice with regard to treatment approach. Although it has been previously noted that, given the heterogeneity of the disorder, it is unlikely that any so-called "one size fits all" treatment could be identified [5], this heterogeneity has been insufficiently taken into account in existing evidence-based treatments [6, 7]. Empirical evidence for a variety of treatments for BPD, such as Transference- 
Focused Psychotherapy; Systems Training for Emotional Predictability and Problem Solving, Dialectical Behavior Therapy, Schema-Focused Therapy, and MentalizationBased Treatment is accumulating [8-10]. However, interpretation of treatment outcome in these studies is hampered by the fact that there may be substantial differences in outcome for different types of BPD patients. Related research on possible differences in response and trajectories of change is also hampered by the relative dearth of research on different subtypes of BPD patients [11]. Hence, in order to address the growing empirical and clinical need to identify which treatments work best for which patients, it is important to identify patient features that may be associated with differential treatment outcome and different trajectories of change. The need to identify meaningful subtypes has been equally stressed in research on developmental pathways involved in BPD (i.e. [4]). Our understanding of the etiology of BPD is currently hampered because of likely differences in etiological pathways toward different phenotypes of BPD [12]. The identification of meaningful subtypes is also important given the growing interest in early detection and intervention in clinical staging models of BPD [13]. This may ultimately lead to improved theoretical frameworks and treatments that are tailored to the specific features and stage of problems presented by a particular BPD patient.

Improved understanding of subtypes may promote refinement of treatment models differentially targeted at salient patient characteristics, thus optimizing the effectiveness of these programs [14]. Several studies have addressed this issue, but results have been quite inconclusive.

\section{The search for subtypes of BPD patients}

Existing research aimed at identifying clinically meaningful subtypes of BPD has, broadly speaking, taken either a variable-centered or a person-centered approach. The former approach has mainly relied on factor analysis, the latter on latent class analysis, cluster analysis, and finite mixture modeling. Variable-centered approaches aim to reduce the wide variety of BPD criteria into a smaller number of underlying dimensions. These studies have typically found evidence for two- to four-factor solutions, encompassing factors such as interpersonal/relational and identity stability; impulsivity and affective instability, consisting of various constellations of the nine BPD criteria [15-17]. Results have been quite inconsistent, which may be due to differences in samples and measures of BPD used [18]. Moreover, correlations among the factors are typically very high, leading some authors to conclude that a more parsimonious onefactor model may fit the data best [19-24]. Elaborating on this knowledge, it has been suggested that BPD may be most adequately described by a one-dimensional model, with factors representing varying degrees of severity on the underlying continuum [21, 24]. Taking into account the evidence demonstrating BPD to be a unidimensional construct, the additional value of investigating the differentiating multiple-factor structures has been noted to be more useful to understand BPD comorbidity and to plan treatment [25].

Variable-based approaches, however, do not allow individual patients to be sorted into meaningful subtypes, and consequently are somewhat limited in their ability to address the question of heterogeneity in BPD [14]. Because individuals may show meaningful combinations of the identified underlying factors of the BPD construct [26], a person-centered approach may be more suitable. Studies comparing both approaches have generally reported evidence for one underlying dimension, with differentiated subtypes [22, 24]. Several studies in samples of clinical (inpatient and outpatient) and nonclinical participants using latent class analysis found clusters that differentiated between (a) individuals with few or no BPD criteria or low likelihood of BPD pathology and (b) individuals with a high number of BPD criteria or high likelihood of BPD pathology [19, 21], thus reflecting differences in the presence and severity of BPD pathology. This has led several authors to stress the need to move beyond differences in terms of severity and broaden the scope of research to features external to diagnostic criteria, in the search for the existence of qualitatively different subtypes among BPD patients [18, 19, 21].

Studies in this area are few, and to date have suggested the existence of two to four subtypes of BPD patients. Leihener et al. [12], for example, found two distinct subtypes based on interpersonal functioning, labeled autonomous and dependent. Salzer et al. [27] differentiated five subtypes based on their characteristic interpersonal patterns: vindictive, moderate submissive, nonassertive, exploitable, and socially avoidant. Zittel, Conklin, Bradley, and Westen [28] identified three subtypes-defined as internalizing dysregulated, externalizing/dysregulated, and histrionic-impulsive-based on a contrast analysis of clinician-rated affect experience and affect regulation. Yet, in an adolescent population, the same group of authors identified four subtypes: high-functioning internalizing, histrionic, depressive internalizing, and angry externalizing [29]. Digre, Reece, Johnson, and Thomas [30] found three subtypes by means of a two-step cluster analysis on demographic, clinical and psychological variables (i.e., age, comorbid diagnosis, coping strategies, suicide attempts and self-harm), which were labeled withdrawn-internalizing, severely disturbed-internalizing, and anxious-externalizing. Lenzenweger et al. [14] performed a theory-based finite mixture modeling analysis, which revealed three phenotypically distinct subtypes of patients, in line with the work of Kernberg and 
colleagues [31]: the first group was characterized by low levels of antisocial, paranoid, and aggressive features; the second by elevated paranoid features; and the third by elevated antisocial and aggressive features. Critchfield, Clarkin Levy, and Kernberg [32] used the same sample of patients, but, by means of Q-factor analysis based on co-occurring PD criteria, they found three subtypes of BPD patients: those with co-occurring cluster A PD traits (elevated schizotypal and paranoid features), those with cluster B PD traits (elevated narcissistic and histrionic features), and those with cluster C PD traits (elevated avoidant and obsessive-compulsive features). Hallquist and Pilkonis [18], by means of finite mixture modeling, found four subtypes that differed in terms of anger/aggressiveness/antisocial behavior and mistrustfulness: an angry-aggressive type with high levels of aggression, antisocial behavior, and dysfunctional bids to maintain interpersonal relationships; an angry/mistrustful type, characterized by considerable concerns about being harmed or exploited in relationships, alongside inappropriate anger; a poor identity/low anger type with poor sense of self and self-injurious behaviors, but low aggressiveness; and a prototypical type with moderate levels of anger but low levels of aggression, antisocial behavior and mistrustfulness. Although there is overlap between the subtypes that have been found in previous studies, no clear consensus has yet been reached on the identification of meaningful subtypes of BPD, resulting at least in part from the various different theoretical and methodological approaches that have been used in defining subtypes. Some studies have used a purely data driven approach, while others have adopted a theory-based approach, leading to multiple categorizations that are difficult to compare with one another. A major limitation of current research in this area is that the thus identified subtypes are often difficult to identify in clinical practice, which limits practical usability with regard to treatment selection or empirical research on treatment outcome. Further reseach on potential subtypes in BPD is therefore needed in a manner that facilitates the applicability of findings in both clinical and empirical practice.

\section{The present study}

In response to the call for more empirical studies that are based on features of BPD [18], we therefore set out to identify subtypes of BPD patients based on information that is commonly available in clinical practice. The present study used a person-centered cluster-analytic approach to identify clusters of BPD patients based on comorbid PD dimensions, building on the study of Critchfield et al. [32]. Based on these commonly available patient characteristics that are often used for treatment selection, we explore whether there are meaningful subgroups that differ based on their PD profiles. The clusters were then validated by investigating their relationship with several domains that are both theoretically and clinically associated with BPD pathology in order to promote the recognizability and applicability of the subtypes in clinical practice. Validation measures included (severity) of borderline pathology, symptom severity, interpersonal problems, quality of life, personality functioning, attachment, and trauma history, in addition to demographic and clinical features. Finally, because a general severity dimension was found to obfuscate attempts to identify meaningful subtypes of BPD patient in earlier efforts [22, 24], we controlled for overall PD severity in all analyses.

\section{Methods}

\section{Participants and procedures}

Participants were 187 outpatients participating in a multicenter randomized controlled trial on the (cost-) effectiveness of day-hospital versus intensive outpatient MBT [2]. Participants were included between March 2009 and July 2014. Patients were referred for MBT at three mental health-care institutions in the Netherlands. All patients underwent a detailed screening and assessment, including semi-structured interviews (described later) to assess axis-I disorders and PDs. Patients were given both verbal and written information on the study, and gave written consent to participate. The study was approved by the Medical Ethics Committee of the Erasmus Medical Center, Rotterdam, the Netherlands. Data were obtained from all screened patients before patients were randomized to either MBT intervention.

Inclusion criteria for this study were having a formal diagnosis of BPD, being 18 years of age or older, and having adequate mastery of the Dutch language. Exclusion criteria were very minimal, comprising diagnosis of an autism spectrum disorder, chronic psychotic disorder, or organic brain disorder that might interfere significantly with the ability to mentalize, and intellectual impairment (IQ < 80). Hence, patients with marked substance abuse or antisocial features were eligible for inclusion in the study.

A total of 226 patients met the inclusion criteria. Thirty-nine patients were excluded because of missing data on the variables used in the cluster analysis $(n=20)$ or because they were extreme outliers, defined as having a score on the input dimension that deviated more than 3.29 standard deviations $(S D)$ from the sample mean on the input variables $(n=19)$, leaving 187 patients for the current study. At baseline, these 187 patients had a mean age of 29.1 years (SD 8.7, range 18-56). The majority of patients $(n=164,88 \%)$ were female. Mean scores on the validation measures for the total sample are presented alongside the cluster means in Table 3.

\section{Input clustering measures}

\section{Personality disorder features dimensional scores}

PDs were assessed using the Structured Clinical Interview for DSM-IV Axis II Personality Disorders (SCID-II; 
$[33,34])$. PD criteria were scored if they were pathological, persistent, and pervasive. Features of the PDs can be scored as 1 (absent), 2 (uncertain), or 3 (positive). Dimensional scores on all 10 PDs were computed by means of the sum of scores on all criteria of the PD. Interviewers were MSc-level psychologists or MSc students who were supervised by an experienced mental health-care psychologist and trained in the SCID-I (see below) and SCID-II by an expert trainer. Previous research has shown that both the original SCID-II and the Dutch version have good inter-rater and test-retest inter-rater reliability [35-37].

\section{Demographic and clinical features \\ Axis-I disorders}

Axis-I disorders ${ }^{1}$ were assessed using the Structured Clinical Interview for DSM-IV Axis I Disorders (SCID-I; $[38,39])$. The SCID-I has good inter-rater reliability $(\kappa=.85)$, especially when interviewers receive training as in the present study [40].

\section{Validation measures}

\section{Borderline symptomatology and severity}

Borderline symptomatology and severity was assessed by means of the Dutch version of the Personality Assessment Inventory borderline features scale (PAI-BOR; [41]). The PAI-BOR is a subscale of the Personality Assessment Inventory [42] and consists of four subscales (each containing six items), which reflect four characteristics of BPD - Affective Instability, Identity Problems, Negative Relationships, and Self-Harm - each with a score range of $0-18$, and a total score range of $0-72$. Both internal consistency of the total score (Cronbach's $\alpha=.81$ ) and subdomains (Cronbach's $\alpha$ range .52-.69), and 6-month test-retest correlation for the sum score (Pearson's $r$.78) and the subdomains (Pearson's $r$ range .60-.75) of the Dutch PAI-BOR are good [41]. Internal consistencies in the current sample were consistent with these estimates, with Cronbach's $\alpha=.81$ for the total score and ranging from .52 to.79 for the subdomains.

\section{Symptomatic severity}

General psychopathological symptoms were assessed with the Dutch version of the Brief Symptom Inventory (BSI; $[43,44])$. The 53-item BSI is the short version of the Symptom Checklist-90-R [45, 46]. The Global Severity Index, with a score range of $0-4$, was used as a global index of symptom distress. The reliability of the Dutch version of the BSI is good (Cronbach's $\alpha$ ranging from .71 to .88 , test-retest reliability $r=.71-.89$; [43]). Internal consistency in the current sample was also high (Cronbach's $\alpha=.97)$.

\section{Social and interpersonal functioning}

Social and interpersonal functioning was assessed by a Dutch version of the Inventory of Interpersonal Problems, using either the 32-item or the 64-item version (IIP; $[47,48])$. The IIP is a self-report measure assessing eight dimensions of interpersonal problems: Domineering/ Controlling, Vindictive/Self-Centred, Cold/Distant, Socially Inhibited, Non-Assertive, Overly Accommodating, SelfSacrificing, and Intrusive/Needy, with subscale scores ranging from 0 to 32 and a total score range of $0-256$. The reliability of the Dutch IIP-64 (Cronbach's $\alpha$ range .73-.85 for subscales and .93-.94 for the total score; $[47,48]$ ) and original IIP-32 (Cronbach's $\alpha$ range $.68-.88$ for subscales and $.73-.85$ for the total score; [49]) are good. In the current sample Cronbach's $\alpha$ was high for the total score for both the 64-item and 32item version; $\alpha=.94$ and $\alpha=.81$ respectivly. Likewise, for the subdomains internal consistency was sufficient, ranging from .66-.86 for the 64-item version, but somewhat lower for some subscales of the 32-item version (Chronbach's $\alpha$ range from .32 to .81).

\section{Quality of life}

Quality of life was measured using the EuroQol EQ-5D3 L [50]. This self-report questionnaire assesses health problems on five dimensions: mobility, self-care, usual activities, pain/discomfort, and anxiety/depression. The dimensions can be summarized into a "value" ranging from -1 to 1 , based on the preferences of the general public. Also, respondents mark their current health on a vertical visual analogue scale (VAS), ranging from 0 (worst imaginable health) to 100 (best imaginable health). The reliability of the EQ-5D-3 L has been found to be acceptable [51]. Internal consistency was sufficient within the current sample (Chronbach's $\alpha=.60)$.

\section{Personality functioning}

Personality functioning was assessed using the Severity Indices of Personality Problems (SIPP; [52]). Either the 60-item (SIPP-SF) or the 118-item (SIPP-118) version was used. The SIPP is a dimensional self-report measure assessing the severity of the changeable components of personality pathology. Higher scores relate to more adaptive personality functioning. In both versions, five higher-order domains are computed: Self-Control, Identity Integration, Responsibility, Relational Capacities, and Social Concordance, with score range of $1-4$. Both the SIPP-118 (Cronbach's $\alpha$ range .69-.84) and SIPP-SF have good psychometric properties [53] and internal consistency within the current sample was high for all domains for both the SIPP-118 (Cronbach's $\alpha$ range .80-.88) and SIPP-SF (Cronbach's $\alpha$ range .79-.88). 


\section{Attachment dimensions}

The Experiences in Close Relationships questionnaire (ECR; [54]), was used to assess attachment avoidance and attachment anxiety. Subscale scores range from 1 to 7. The Dutch version of the ECR was found to be a valid measure with good internal (Cronbach's $\alpha$ range .86-.93) and external validity [55]. Internal consistency for the current sample was high for both the attachment avoidance (Cronbach's $\alpha=.94$ ) and anxiety subscale (Cronbach's $\alpha=.90)$.

\section{Trauma}

The prevalence of trauma in childhood was measured by means of a Dutch translation of the short form of the retrospective self-report Childhood Trauma Questionnaire (CTQ; [56]), which measures five categories of childhood trauma experience: emotional, physical, and sexual abuse, and emotional and physical neglect. Subscale scores range from 5 to 25 and the total score from 25 to 125 . Both the original CTQ version (Cronbach's $\alpha$ range .61-.95; $[56,57]$ ) and the Dutch translation (Cronbach's $\alpha$ range $.63-.95$; [58]) have adequate psychometric properties. Internal consistencies in the current sample were consistent with these estimates, with Cronbach's $\alpha=.93$ for the total score and ranging from .63 to .91 for the subdomains.

\section{Statistical analysis}

All analyses were performed in SPSS version 23.0. The 10 PD dimensions served as input variables for the cluster analysis. Since the primary interest lay in the patterning across PD features, as opposed to identifying an overall severity level, all dimensional scores were adjusted for the overall severity of personality pathology (i.e., each cases' own mean score of PD features on the SCID-II), thereby eliminating within each person the influence of their overall severity on the PD profile. A two-phased clustering procedure was used following recent state-of-the art recommendations, described in detail in Gore [59]. The first step involved a hierarchical cluster analysis, by means of Ward's method with squared Euclidean distances [60]. In the second step, the cluster-center means extracted through this hierarchical analysis were used as nonrandom starting points in a $k$-means cluster analysis [61]. This iterative procedure solves a major shortcoming of the hierarchical method, namely, that once a case is assigned to a cluster; it cannot be reassigned to another cluster in a subsequent stage. In the $k$-means clustering procedure the within-cluster variance on criterion variables is minimized, while differences between clusters are maximized, allowing reassignment of cases to a better fitting cluster, thus optimizing cluster membership [59]. Hence, the hierarchical cluster analysis based on dimensional scores on the PD dimensions was used to define clusters with distinct meaningful and coherent profiles representing different BPD subtypes. Subsequently, k-means clustering was used to assign individuals to their best fitting-cluster. This two-phased procedure that starts with a decision on the number of clusters, was repeated for the assumption of a 2-, 3-, 4-, 5- and 6 cluster solution. Different cluster solutions were compared with regard to the proportion of variance in the 10 input PD dimensions that was explained by the cluster solution (multivariate $R^{2}$; 1 -Wilks' lambda $(\Lambda)$ ) and a more conservative measure of the proportion of the variance that was accounted for by the cluster solution, taking into account the error factor in the analysis $\left(\right.$ partial $\eta^{2}$ ). The fit of the cluster solutions was also compared based on multiple information criteria: the Akaike Information Criterion [62], Schwarz's Bayesian Information Criterion [63], Calinski-Harbasz Index [64], and Silhouettes [65]. Based on explanatory power, fit indices, parsimony, and interpretability, the best fitting model cluster solution was determined.

Kendall's tau ( $\mathbf{\tau})$ was used to investigate the relationships between the input dimensions. The clusters were then compared on the input dimensions by means of multivariate analysis of variance (MANOVA) with GamesHowell post-hoc comparisons. Because the clusters were defined using $z$-standardized scores, the cluster means are deviation scores from the total sample mean, with $M=0$ and $S D=1$. Thus, each cluster's mean $z$-score indicated how far the cluster deviated from the total sample mean score (0) and from the means of the other clusters. $[66,67]$. Discriminant analysis was used to investigate the dimensions underlying and accounting for the distinct clusters.

Finally, clusters were compared on external validation measures by means of chi-square tests or (M)ANOVA with Games-Howell post-hoc test, as appropriate. In case of violation of assumption of expected frequencies, Fisher's exact test was used (chi-square test), and in case of violation of the assumption of equality of variances Welch's $F$ statistic was used (ANOVA). Effects sizes (ES) for the external validation measures were computed in the same manner as described above. As a result of missing data, sample sizes differ for each (M)ANOVA per instrument.

\section{Results \\ Sample characteristics}

Of the 187 patients included in the study, 80\% $(n=149)$ had at least one axis-I disorder (range 0-6). Mood disorders were most frequently diagnosed $(n=100,54 \%)$, followed by anxiety disorders $(n=75,40 \%)$, substance use disorders ( $n=54,29 \%)$, and eating disorders ( $n=49,26 \%)$. About one third of patients was diagnosed with more than one PD $(n=58,31 \%)$. Besides BPD, avoidant PD was most prevalent $(n=18,10 \%)$. Cluster 
C PD traits were the most prevalent comorbid PD traits $(n=131,72 \%)$. Of all patients, $53 \%(n=100)$ had at least one avoidant PD feature, $34 \%(n=63)$ at least one dependent PD feature, and 32\% $(n=60)$ at least one obsessive-compulsive PD feature. For cluster B features, $12 \%(n=23)$ of patients had at least one narcissistic PD feature, $12 \%(n=22)$ at least one antisocial PD feature, and $6 \%(n=12)$ at least one histrionic PD feature. Cluster A features were least prevalent; although $18 \%$ $(n=34)$ had at least one paranoid PD feature, only 6\% $(n=12)$ had at least one schizotypal PD feature, and only one patient had a schizoid PD feature.

\section{Subtypes of BPD patients based on two-phase cluster analysis}

Significant correlations between several of the PD dimensions were found, even after correcting for severity, ranging from $\tau=-.32$ to $\tau=.74 .^{2}$ Inspection of the percentage of variance in the personality dimensions that was accounted for by the cluster solution (multivariate $R^{2}$ ) revealed that the two-factor solution explained $81.0 \%$ of the total variance. A three-cluster solution explained 97.3\% of the variance. The improvement in explained variance was very small for the four-, five-, and six-cluster solutions (99.1, 99.7, and 99.9\%, respectively), suggesting that a three-factor solution was optimal in terms of parsimoniousness and explained variance. This assumption was confirmed when considering the more conservative measure of the proportion of variance accounted for by the cluster solution, by adding the influence of an error factor (partial $\eta^{2}$ ). Partial $\eta^{2}$ was also highest for the threecluster solution (.84) compared with the two- to fivecluster solutions (respectively, .81, .79, .77, and .76). A sixcluster solution consisted of clusters containing very few patients (smallest cluster $n=3$ ) and could not be meaningfully interpreted. Exploration of fit criteria for the two-, three-, four-, and five-cluster solutions showed inconsistent results (see Table 1). Because of parsimony and interpretability, the three-cluster model was retained.

Figure 1 illustrates the final cluster solution. Cluster 1 was the largest cluster, consisting of $76 \%$ of the sample $(n=145)$. Patients in this cluster showed the highest relative levels of BPD features compared with the two

Table 1 Fit indices of optimal cluster solution

\begin{tabular}{lllll}
\hline Cluster solution & AIC & BIC & CH & S \\
\hline Two clusters & 1144.66 & 1273.91 & 24.58 & $.325^{\mathrm{a}}$ \\
Three clusters & 1068.20 & $1262.06^{\mathrm{a}}$ & 25.24 & .313 \\
Four clusters & 1043.13 & 1301.62 & 24.95 & .309 \\
Five clusters & $971.74^{\mathrm{a}}$ & 1294.85 & $28.15^{\mathrm{a}}$ & .248
\end{tabular}

AIC Akaike Information Criterion, BIC Schwarz's Bayesian Information Criterion, $\mathrm{CH}$ Calinski-Harabasz Index, and $S$ Silhouettes

aptimal fit according to this criterion. A better fit of the cluster solution to the data is indicated by higher $\mathrm{CH}$ and $\mathrm{S}$ scores, and lower AIC and BIC scores other clusters and no marked elevations on the other dimensions. We therefore labeled this cluster "Core BPD". The second cluster consisted of a smaller number of patients $(14 \%, n=27)$. We labeled this cluster "Extravert/ externalizing," because an outward-oriented/externalizing attitude seemed to be a common denominator in the narcissistic, antisocial, and histrionic PD dimensions on which the cluster differentiated from the other two clusters. The smallest cluster consisted of $8 \%$ of the patients $(n=15)$, and was labeled "Schizotypal/paranoid" because of the elevated levels on these PD dimensions.

A MANOVA showed a significant difference between the three clusters on the clustering dimensions, $\Lambda=.027, F(20,350)=88.429, p<.001$. Clusters differed significantly on all PD dimensions except for the BPD dimension itself, and the dependent and obsessive-compulsive PD dimension (see Table 2). The Schizotypal/paranoid cluster differed markedly from the other clusters, as expressed in very high ES on the schizotypal and paranoid PD dimensions. The Extravert/externalizing cluster differed from the other clusters, as expressed in very high ES on the narcissistic, antisocial, and histrionic PD dimension (see also Fig. 1). Compared with the other two clusters, the Extravert/externalizing cluster scored very low on the avoidant PD dimension, resulting in a significant difference between the Core BPD and Extravert/externalizing cluster.

The MANOVA was followed up with a discriminant analysis, which revealed two discriminant functions. The first explained $68.1 \%$ of the variance, canonical $R^{2}=.88$, and the second $31.9 \%$, canonical $R^{2}=.76$. These discriminant functions significantly differentiated between the clusters, both in combination $(\Lambda=.027$, $\left.X^{2}(20)=646.41, p<.001\right)$ and when the first function was removed $\left(\Lambda=.226, \chi^{2}(9)=266.66, p<.001\right)$. To make interpretation easier, the discriminant functions were named based on their most distinctive aspects: Function 1 as "Schizotypal variate" and Function 2 as "Narcissistic, antisocial, histrionic variate". The discriminant plot and group centroids showed that the first function, to which the schizotypal dimension $(r=.924)$ was most strongly correlated, discriminated the Schizotypal/paranoid cluster from the other clusters. The second function to which the narcissistic $(r=.526)$, antisocial $(r=.324)$ and histrionic PD dimensions $(r=.311)$ were highly correlated, discriminated the second Extravert/externalizing cluster from the other two clusters.

\section{Validation of the clusters Demographic and clinical features}

The Extravert/externalizing cluster was composed of significantly more men $(37 \%, n=10)$ than the Core BPD cluster $(8 \%, n=11)$ and the Schizotypal/paranoid cluster 


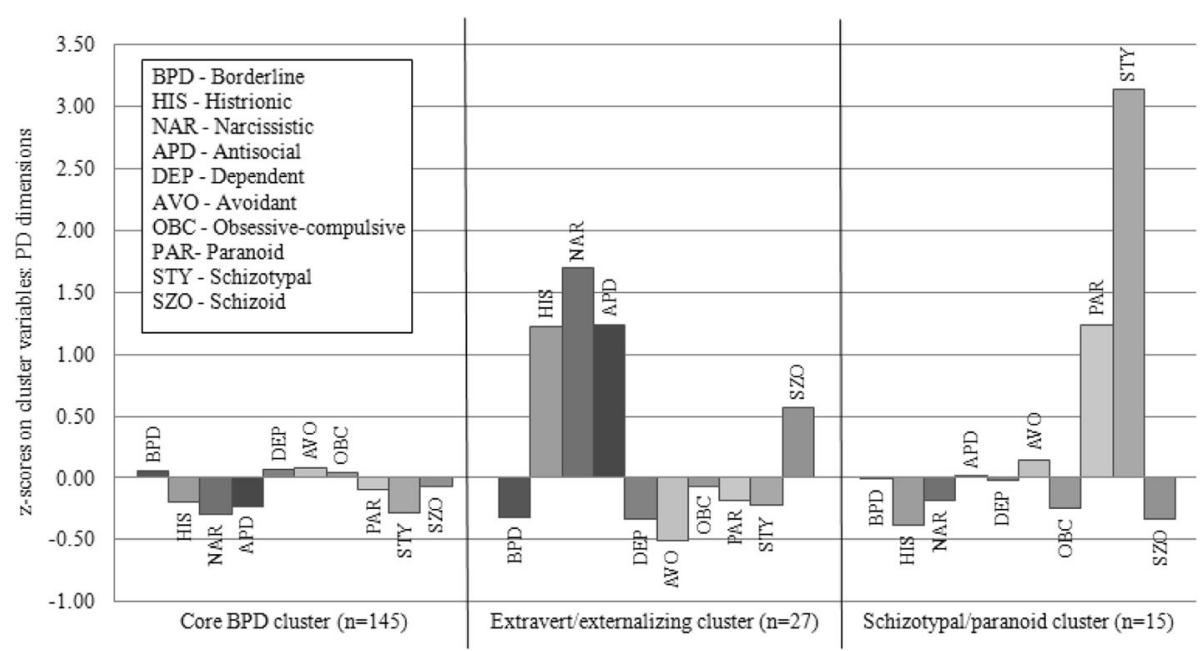

Fig. 1 Z-scores on personality dimensions for the final 3-cluster solution. Z-scores below 0 represent lower and above 0 higher scores compared to the total sample mean

(13\%, $n=2), p<.001$ (Fisher's exact test). Clusters did not differ significantly on other demographic characteristics, such as having daytime activities $\left(x^{2}(2)=.59\right.$, $p=.761)$, living environment $(p=.991$, Fisher's exact test), or age $(F(2,184)=.76, p=.469)$.

The clusters differed significantly in number of axis-I disorders $(F(2,184)=4.10, p=.018)$. Patients in the Extravert/externalizing cluster had significantly fewer axis-I disorders $(M=1.3, S D=1.0)$ than those in the Schizotypal/paranoid $(M=2.5, S D=1.2, p=.007)$ and Core BPD $(M=1.9, S D=1.5, p=.027)$ clusters.

\section{Validation measures}

Table 3 shows cluster means and ES for the other validation measures. A trend on the MANOVA for borderline pathology (PAI-BOR, $\Lambda=.91, F(8,302)=1.73$, $p=.091)$ was found. Follow-up ANOVAs showed a significant difference between the clusters for the total PAI-BOR score $(F(2,154)=3.60, p=.030)$, which did not result in significant post-hoc comparisons. Significant differences between the clusters were found for the Affective Instability $(F(2,154)=3.70, p=.027)$ and Identity Problems $(F(2,154)=4.66, p=.011)$ subscales. The Games-Howell post-hoc test showed that patients in the Extravert/externalizing cluster tended to report less affective instability, but this trend did not reach significance $(p=.065)$. However, Extravert/externalizing patients did report significantly less identity problems ( $p=.027)$ compared with those in the Core BPD cluster.

A trend was found between the clusters on symptomatic severity (BSI; $F(2,162)=2.56, p=.081)$, with patients in the Core $B P D$ cluster reporting the highest

Table 2 Differences on personality dimensions for the three-cluster solution

\begin{tabular}{|c|c|c|c|c|c|c|c|c|}
\hline \multirow[t]{2}{*}{ PD dimension } & \multicolumn{2}{|c|}{ Core BPD } & \multicolumn{2}{|c|}{ Extravert/externalizing } & \multicolumn{2}{|c|}{ Schizotypal/Paranoid } & \multirow[t]{2}{*}{$F$} & \multirow[t]{2}{*}{ Games-Howell Post-hoc comparison and $d$} \\
\hline & $M$ & $S D$ & $M$ & $S D$ & $M$ & $S D$ & & \\
\hline Borderline & .06 & 1.01 & -.32 & .94 & -.01 & 1.01 & 1.618 & \\
\hline Histrionic & -.19 & .50 & 1.22 & 1.98 & -.38 & .14 & $31.715^{* * *}$ & $2>1,3(d=1.41 ; 1.60) ; 1>3(d=.19)$ \\
\hline Narcissistic & -.30 & .41 & 1.69 & 1.58 & -.18 & .63 & $87.427^{* * *}$ & $2>1,3(d=1.99 ; 1.87)$ \\
\hline Antisocial & -.23 & .44 & 1.24 & 1.87 & .01 & 1.12 & $32.993^{* * *}$ & $2>1,3(d=1.47 ; 1.23)$ \\
\hline Dependent & .06 & 1.04 & -.33 & .79 & -.02 & .88 & 1.837 & \\
\hline Avoidant & .08 & 1.02 & -.51 & .61 & .15 & 1.13 & $4.283^{*}$ & $2<1(d=.59)$ \\
\hline Obsessive-compulsive & .04 & 1.02 & -.07 & .90 & -.25 & 1.00 & .637 & \\
\hline Paranoid & -.10 & .95 & -.18 & .59 & 1.24 & 1.27 & $14.413^{* * *}$ & $3>1,2(d=1.34 ; 1.42)$ \\
\hline Schizotypal & -.28 & .26 & -.22 & .43 & 3.13 & .90 & $573.271^{* * *}$ & $3>1,2(d=3.41 ; 3.35)$ \\
\hline Schizoid & -.07 & .60 & .57 & 2.13 & -.34 & .61 & $5.882^{* *}$ & ns \\
\hline
\end{tabular}

The last column summarizes the significant post-hoc comparisons with corresponding effect sizes (Cohen's $d$ ) between the cluster means per dimension; $>$ corresponds to a higher dimensional score and $<$ to a lower dimensional score. ${ }^{*} p<.05,{ }^{* *} p<.01,{ }^{* * *} p<.001$ 
Table 3 Cluster means and effect sizes on validation measures

\begin{tabular}{|c|c|c|c|c|c|c|c|c|c|c|c|c|}
\hline & & \multicolumn{2}{|c|}{ Core BPD $(n=83-125)^{a}$} & \multicolumn{2}{|c|}{$\begin{array}{l}\text { Extravert/externalizing } \\
(n=11-19)^{\mathrm{a}}\end{array}$} & \multicolumn{2}{|c|}{$\begin{array}{l}\text { Schizotypal/paranoid } \\
(n=9-14)^{\mathrm{a}}\end{array}$} & \multicolumn{2}{|c|}{ Total $(n=103-165)^{\mathrm{a}}$} & \multicolumn{3}{|c|}{ Cohen's d } \\
\hline & & M & $S D$ & M & $S D$ & M & $S D$ & M & $S D$ & $1-2$ & $1-3$ & $2-3$ \\
\hline \multirow[t]{5}{*}{ PAI-BOR } & Total & 48.45 & 9.51 & 42.95 & 11.62 & 43.46 & 11.74 & 47.37 & 10.13 & .54 & .49 & .05 \\
\hline & Identity Problems & 12.76 & 3.24 & 10.53 & 3.26 & 11.31 & 3.30 & 12.37 & 3.32 & .67 & .44 & .24 \\
\hline & Affective Instability & 13.66 & 2.71 & 11.79 & 3.26 & 12.85 & 3.95 & 13.37 & 2.94 & .64 & .28 & .36 \\
\hline & Negative Relationships & 12.68 & 2.95 & 11.68 & 3.30 & 12.00 & 3.14 & 12.50 & 3.01 & .33 & .23 & .10 \\
\hline & Self-Harm & 9.34 & 4.25 & 8.95 & 4.18 & 7.31 & 4.17 & 9.13 & 4.25 & .09 & .48 & .39 \\
\hline BSI & Total & 1.91 & .76 & 1.49 & .89 & 1.71 & .90 & 1.84 & .79 & .53 & .24 & .28 \\
\hline \multirow[t]{9}{*}{$\| P$} & Total & 112.32 & 39.98 & 96.35 & 35.86 & 110.18 & 42.07 & 110.19 & 39.79 & .40 & .05 & .35 \\
\hline & Domineering/Controlling & 9.50 & 5.72 & 11.00 & 6.10 & 8.43 & 5.24 & 9.59 & 5.72 & .26 & .19 & .45 \\
\hline & Vindictive/Self-Centered & 11.75 & 5.53 & 11.68 & 6.42 & 13.07 & 6.16 & 11.86 & 5.67 & .01 & .23 & .24 \\
\hline & Cold/Distant & 13.21 & 7.41 & 12.84 & 7.09 & 13.21 & 6.39 & 13.17 & 7.24 & .05 & .00 & .05 \\
\hline & Socially Inhibited* & 16.24 & 8.45 & 11.56 & 6.57 & 16.21 & 5.91 & 15.66 & 8.16 & .57 & .00 & .57 \\
\hline & Overly Accomodating & 15.56 & 7.50 & 12.26 & 6.57 & 15.43 & 8.93 & 15.15 & 7.56 & .44 & .02 & .42 \\
\hline & Non-Assertive* & 16.36 & 7.84 & 10.63 & 6.18 & 17.53 & 8.26 & 15.76 & 7.90 & .72 & .15 & .87 \\
\hline & Self-Sacrificing ${ }^{b}$ & 17.29 & 6.94 & 13.95 & 6.32 & 16.00 & 6.66 & 16.77 & 6.89 & .48 & .19 & .30 \\
\hline & Intrusive/Needy & 12.43 & 5.45 & 12.42 & 5.27 & 10.30 & 5.32 & 12.23 & 5.42 & .00 & .39 & .39 \\
\hline \multirow[t]{2}{*}{ EQ-5D } & Total** & .48 & .28 & .65 & .17 & .60 & .30 & .51 & .28 & .59 & .43 & .16 \\
\hline & EQ-VAS & 57.15 & 19.29 & 62.12 & 16.64 & 70.23 & 24.61 & 58.82 & 19.76 & .25 & .65 & .40 \\
\hline \multirow[t]{5}{*}{ SIPP } & Self-Control & 2.10 & .60 & 2.29 & .66 & 2.17 & .55 & 2.12 & .60 & .32 & .11 & .20 \\
\hline & Identity Integration* & 1.90 & .60 & 2.42 & .65 & 1.88 & .62 & 1.95 & .63 & .83 & .03 & .86 \\
\hline & Responsibility & 2.60 & .57 & 2.52 & .69 & 2.75 & .47 & 2.60 & .57 & .13 & .26 & .39 \\
\hline & Relational Capacities & 2.29 & .64 & 2.50 & .62 & 2.39 & .43 & 2.32 & .63 & .34 & .16 & .18 \\
\hline & Social Concordance & 2.78 & .60 & 2.72 & .66 & 2.83 & .45 & 2.78 & .59 & .11 & .08 & .19 \\
\hline \multirow[t]{2}{*}{ ECR } & Anxiety & 5.09 & 1.17 & 4.67 & .96 & 5.17 & .52 & 5.06 & 1.21 & .38 & .07 & .45 \\
\hline & Avoidance & 3.70 & 1.29 & 3.77 & 1.52 & 3.57 & 1.44 & 3.70 & 1.32 & .05 & .10 & .15 \\
\hline \multirow[t]{6}{*}{ CTQ } & Total & 54.78 & 19.09 & 61.09 & 22.00 & 56.22 & 19.75 & 55.58 & 19.36 & .33 & .07 & .25 \\
\hline & Emotional Abuse ${ }^{b}$ & 14.22 & 6.02 & 17.55 & 6.04 & 15.22 & 6.87 & 14.66 & 6.12 & .54 & .16 & .38 \\
\hline & Emotional Neglect & 15.13 & 5.60 & 17.45 & 6.04 & 16.22 & 6.00 & 15.48 & 5.68 & .41 & .19 & .22 \\
\hline & Physical Abuse & 7.72 & 4.61 & 8.64 & 5.64 & 6.89 & 3.52 & 7.75 & 4.62 & .20 & .18 & .37 \\
\hline & Physical Neglect & 8.90 & 3.58 & 9.73 & 4.10 & 9.22 & 3.27 & 9.02 & 3.59 & .23 & .09 & .14 \\
\hline & Sexual Abuse & 8.81 & 5.55 & 7.73 & 5.97 & 8.67 & 4.90 & 8.68 & 5.50 & .20 & .03 & .17 \\
\hline
\end{tabular}

PAI-BOR Personality Assessment Inventory borderline features scale, BSI Brief Symptom Inventory, EQ-5D EuroQol EQ-5D-3 L, SIPP Severity Indices of Personality Problems, ECR Experiences in Close Relationships questionnaire, CTQ Childhood Trauma Questionnaire

${ }^{\mathrm{a}}=\mathrm{n}$ varies due to missing values. Cohen's $d$ columns show effect sizes between, respectively, clusters $1-2,1-3$, and $2-3$. ${ }^{* *}$ Significant in (M)ANOVA at $p<.05$.

*Marginally significant in (M)ANOVA with moderate to large ES

${ }^{b}$ Probable distinguishing based on moderate ES

symptomatic severity, and the Schizotypal/paranoid and the Extravert/externalizing clusters reporting below overall sample mean symptomatic severity.

No significant differences between the clusters were found in an overall MANOVA on interpersonal problems (IIP; $\Lambda=.84, F(18,290)=1.45, p=.107$ ). Separate ANOVAs for each subscale showed that the clusters differed only on the Socially Inhibited (Welch statistic, $p=.032)$ and Non-Assertive $(F(2,153)=4.95, p=.008)$ subscales. A Games-Howell post-hoc test showed that patients in the Extravert/externalizing cluster had significantly less interpersonal problems related to social inhibition than those in the Core BPD cluster $(p=.026)$. The Extravert/externalizing cluster reported significantly less interpersonal problems related to nonassertiveness, in comparison to the elevated scores for nonassertiveness in the other two clusters.

A significant difference was found between the clusters for quality of life (EQ), $\Lambda=.94, F(4,298)=2.56$, $p=.039$. A follow-up ANOVA showed a significant 
difference between the clusters on the EQ score $(p=.021)$ by means of the Welch statistic. Patients in the Core BPD cluster reported the lowest quality of life and scored significantly lower than patients in the Extravert/externalizing cluster, who reported the highest quality of life $(p=.006)$. A trend was found for the EQ VAS score $(F(2,151)=2.50, p=.085)$, with the Schizotypal/ paranoid cluster having highest self-reported health, followed by the Extravert/externalizing cluster and then the Core BPD cluster, which reported below the (overall) mean state of health, although post-hoc tests did not reach significance.

No significant differences were found on personality functioning (SIPP; $\Lambda=.91, F(10,300)$, $=1.54, p=.124)$ ), attachment (attachment avoidance; $F(2,141)=.075, p=.928$; attachment anxiety, Welch statistic $p=.258$ ), or trauma history (CTQ; $\Lambda=.945, F(10,192)=.553, p=.850)$.

Moderate ES (see also Table 3) represented differences between the clusters in terms of symptomatic severity, quality of life, attachment style (specifically in terms of attachment anxiety), emotional abuse, and emotional neglect, and overall severity of borderline pathology, as well as affective instability and identity problems. The latter finding is confirmed by a large ES on Identity Integration. In order to enhance interpretability, the directions of the differences based on ES are summarized as (potentially) distinguishing features between the clusters in Fig. 2, which also presents the similarities between the clusters.

\section{Discussion}

Results of this study showed three meaningful clusters of BPD patients with distinctive profiles, suggesting three potential subtypes of BPD: (a) a Core BPD, (b) an Extravert/externalizing, and (c) a Schizotypal/paranoid subtype. The subtypes were clearly gendered, in that men were remarkably more prevalent within the Extravert/externalizing subtype compared with the total sample and the other subtypes. In addition, subtypes differed in terms of quality of life and number of comorbid symptoms, with the Extravert/externalizing subtype reporting the highest quality of life and lowest number of axis-I disorders. Trends were found for domains of interpersonal problems and borderline pathology severity, the latter specifically in terms of affective dysregulation and identity problems, with the Extravert/externalizing subtype again reporting the least problems in these domains. Probable distinguishing features between the subtypes included specific aspects of personality functioning and attachment. The remarkable differences in the number of patients per cluster, with the Core BPD cluster containing five times as many patients as the Extravert/ externalizing cluster and almost 10 times as many patients as the Schizotypal/paranoid cluster may be an important finding in itself. However, further replication of this finding is needed, as it may be influenced by the specific treatment setting, and/or the results may indicate that the Extravert/externalizing and Schizotypal/ paranoid patients are less inclined to seek treatment.

The Core BPD subtype had relatively more BPD features, but was mainly characterized by the absence of marked elevation on any of the other PD dimensions. This subtype resembles the nonaggressiveness/nonparanoid/nonantisocial subtype of Lenzenweger et al. [14] and the avoidant/obsessive-compulsive subtype reported by Critchfield et al. [32], in terms of the similar presence of avoidant features, and the anaclitic BPD type reported by Blatt and Auerbach [68]. The Core BPD subtype appears to represent the prototypical BPD patients for whom most evidence-based treatments seem to be initially developed. These patients generally reported the highest symptomatic severity and personality pathology. This group did not clearly differentiate on either attachment avoidance or attachment anxiety, which might suggest a disorganized attachment style. Their pattern of interpersonal problems showed ambivalence in terms of an internalizing style characterized by social inhibition, nonassertiveness, and being overly accommodating on the one hand, while, on the other hand, having a high need for closeness and an intrusive, dominant, controlling style. The contradictory phenomenon of the high need for intimacy and simultaneous experience of high anxiety in response to intimacy is often observed clinically in these patients. In accordance with this, Core BPD patients reported marked relational problems, but also instability in identity and self-control. Remarkably, though, these patients reported the lowest levels of early childhood trauma. This contrasts with theories that suggest an important role for environmental adversity, but supports theories that point to the importance of biological vulnerability in the etiology of BPD [7, 69]. However, because levels of trauma were overall high in the total sample, it should be borne in mind that differences between the subtypes are relative, and that ES of differences in trauma between subtypes were small for most categories of trauma. Moreover, Weinstein et al. [70] have pointed to the importance of focusing on specific types of childhood trauma. Although different forms of trauma were assessed in this study, the evaluation of childhood trauma was not exhaustively assessed (i.e., there was a lack of assessment of more subtle forms of unavailability of the caregiver who has the child in mind, which has previously been mentioned as an important influential factor in the etiology of BPD pathology; [7]). Moreover, possible confounding of the concept of dissociation in the relationship between trauma and BPD pathology [70] was not accounted for in this study, and this might have influenced our findings. 


\begin{tabular}{|c|c|c|}
\hline 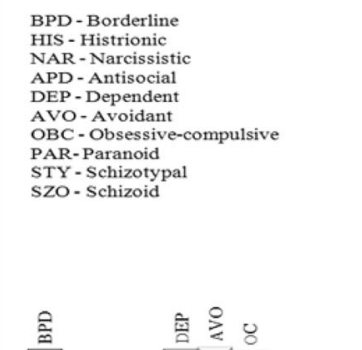 & 妾 & $\stackrel{?}{2}$ \\
\hline Core BPD cluster (n=145) & $\left|\begin{array}{c}\text { 商 } \\
\text { Extravert/externalizing cluster }(\mathrm{n}=27)\end{array}\right|$ & Schizotypal/paranoid cluster (n=15) \\
\hline Core $B P D(n=145)$ & $\begin{array}{l}\text { Extravert/externalizing }(\mathrm{n}=\mathbf{2 7}) \\
\text { Distinguishing features* }\end{array}$ & Schizotypal/paranoid (n=15) \\
\hline $\begin{array}{l}\text { - } 8 \% \text { male } \\
\text { - Lowest quality of life } \\
\text { - Highest level of symptomatic } \\
\text { severity } \\
\text { - Highest overall severity of BPD } \\
\text { pathology; particularly affective } \\
\text { instability \& identity problems } \\
\text { - Interpersonal problems of non- } \\
\text { assertiveness and social inhibition }\end{array}$ & $\begin{array}{l}\text { - } 37 \% \text { male } \\
\text { - Highest quality of life } \\
\text { - Lowest level of symptomatic severity \& } \\
\text { lowest prevalence of axis-I disorders } \\
\text { - Lowest overall severity of BPD } \\
\text { pathology, affective instability \& identity } \\
\text { problems } \\
\text { - Less interpersonal problems of non- } \\
\text { assertiveness and social inhibition }\end{array}$ & $\begin{array}{l}\text { - } 13 \% \text { male } \\
\text { - Highest prevalence of axis-I } \\
\text { disorders } \\
\text { - Intermediate symptom distress } \\
\text { - Highest self-reported health } \\
\text { - Interpersonal problems of non- } \\
\text { assertiveness and social inhibition }\end{array}$ \\
\hline & Probable distinguishing features** & \\
\hline $\begin{array}{l}\text { - Lowest personality functioning in } \\
\text { terms of identity integration, } \\
\text { relational capacities and } \\
\text { selfcontrol } \\
\text { - Ambivalent interpersonal style: } \\
\text { self-sacrificing, overly } \\
\text { accommodating, socially inhibited, } \\
\text { but also intrusive/needy and } \\
\text { domineering/controlling } \\
\text { - Higher on both anxious and } \\
\text { avoidant attachment: disorganized } \\
\text { attachment pattern } \\
\text {-Highest reports of self-harm }\end{array}$ & $\begin{array}{l}\text { - Higher personality functioning in terms } \\
\text { of selfcontrol, relational capacities \& } \\
\text { identity integration functioning, but not } \\
\text { on domains of responsibility and social } \\
\text { concordance } \\
\text { - High on domineering/controlling, low } \\
\text { on social inhibition, non-assertiveness, } \\
\text { self-sacrifice and overly accommodating } \\
\text { - Highest prevalence of emotional abuse } \\
\text { and emotional neglect in trauma history } \\
\text { - Mostly avoidant attachment }\end{array}$ & $\begin{array}{l}\text { - Highest scores on personality } \\
\text { functioning in terms of } \\
\text { responsibility \& social concordance } \\
\text { - Lowest reports of self-harm } \\
\text { - Also socially inhibited, overly } \\
\text { accommodating, but mostly non- } \\
\text { assertive and also vindictive, self- } \\
\text { centered style, low on self-sacrifice } \\
\text { and needy/intrusive } \\
\text { - Mostly anxious attachment } \\
\text { - Lowest on self-harm }\end{array}$ \\
\hline \multicolumn{3}{|c|}{ ies *** } \\
\hline \multicolumn{3}{|c|}{$\begin{array}{l}\text { - Borderline, obsessive compulsive, dependent, schizoid features } \\
\text { - Cold/distant \& vindictive/self-centered interpersonal style } \\
\text { - Trauma history of physical abuse, physic al neglect and sexual abuse } \\
\text { - Anxious attachment } \\
\text { - Social Concordance }\end{array}$} \\
\hline
\end{tabular}

Fig. 2 Distinguishing, probable distinguishing features and similarities of the clusters.

All features are relative compared to the other clusters (as oposed to norm groups). *Significant distinguishing based on significant ANOVA. ** Probable distinguishing based on moderate $(>.5)$ or large ES $(>.8)$. ** Similarities based on small ES $(<.2)$

The Extravert/externalizing subtype was labeled as such because an outward-oriented/externalizing attitude seemed to be a common denominator in the narcissistic, antisocial, and histrionic PD dimensions on which this subtype differentiated from the other two subtypes. Correspondingly, this subtype scored very low on the avoidant PD dimension, in contrast to the other two subtypes. This subtype resembles similar subtypes of patients found by Critchfield et al. [32] and Lenzenweger et al. [14] (i.e., labeled narcissistic and histrionic, and antisocial/aggressive/nonparanoid, respectively) and the introjective BPD type reported by Blatt and Auerbach
[68]. These patients reported relatively low symptomatic severity and generally more adaptive levels of personality functioning, with their interpersonal functioning being characterized by a dominant, self-centered style. It could be hypothesized that these externalizing patients have a tendency to deny distress and/or may experience less problems or burden. Caligor, Kernberg, and Clarkin [71] have described such a subtype of patients that seems to be able to function relatively stable in certain domains. Nevertheless, it could be expected that these patients have problems adjusting to social norms, as a result of their externalizing style. This was confirmed by 
impairments on domains of responsibility and social concordance, which cover aspects of personality functioning such as responsibility, trustworthiness, respect, and cooperation. These patients are often known for their high levels of dismissive attachment and indeed scored higher on attachment avoidance compared to the other subtypes. Perhaps surprisingly, this subtype reported more childhood trauma (especially emotional abuse and emotional neglect) compared with the other subtypes; this might reflect a relatively more important role for environmental factors in the etiology of BPD in these patients [7]. Men were overrepresented in this subtype, which might indicate a gendered expression of BPD pathology, marked by a tendency for men to externalize problems. However, results may also indicate that internalizing male BPD patients are less likely to seek treatment or to be referred for treatment. The subtype of patients with BPD and comorbid narcissistic and antisocial PD features has previously been identified as a group that poses significant clinical challenges and might be more treatment resistant [72], necessitating a somewhat different treatment approach (i.e., [71]). Indeed, the developers of several current evidence-based treatments initially developed for BPD have adapted their core models and treatment programs for this subtype [72-74].

The third subtype, Schizotypal/paranoid, was labeled as such because of the elevated levels of schizotypal and, to lesser extent, paranoid features that were evident. This subtype appears quite similar to the cluster A subtype with elevated schizotypal paranoid features identified by Critchfield et al. [32], and to the paranoid/ nonaggressive/nonantisocial group reported by Lenzenweger et al. [14]. Questions arise whether this subtype may (partly) represent a group of patients with higher risk for psychosis, as schizotypy has been described as being associated with developing psychotic spectrum disorder [75]. The group shares some commonalities with the borderline schizophrenia subtype reported by Blatt and Auerbach [68]; however, these authors mention that patients meeting criteria for both BPD and schizotypal PD (as is the case in this subtype) are most likely to be introjective individuals, who are differentiated from the borderline schizophrenia subtype by having more intact perceptual processes and less vulnerability to fully psychotic states (although transient, reversible psychotic regressions may be present in introjective patients). Badoud al. [76] also underlined the fact that similar symptoms (such as psychotic manifestations) may be different in nature and duration when occurring in the context of borderline pathology versus schizotypal pathology, and may need a different treatment approach. The fact that a separate subtype emerged with marked elevations on this dimension underlines the importance of investigating this trait within BPD patients. Despite the fact that co-occurrence of schizotypal traits and BPD is widely documented, and is generally considered to be challenging to treat [76], current treatment manuals do not propose specific adaptations to their approaches for these patients. This subtype might be less inclined to seek treatment or less able to get into treatment, which may also in part explain why this cluster was so small. Patients within this subtype report relatively more stable functioning in terms of responsibility and social concordance and higher self-reported health. This may be accounted for by the fact that these patients seem to function in a socially isolated way, resulting in them experiencing less distress. Although problems occur in interpersonal relationships related to social inhibition and being overly accommodating, similar to the Core $B P D$ subtype, the Schizotypal/paranoid subtype does not show the same ambivalence, and there is no intrusive interpersonal style in need for closeness, as is the case in the Core BPD subtype. In contrast, this subtype shows more problems concerning hostile dominance, which is marked by mistrust. They also exhibit lower levels of self-sacrifice in comparison to the Core $B P D$ subtype, but show a lack of self-confidence and problems with assertiveness. The Schizotypal/paranoid subtype showed highest levels of attachment anxiety compared to the other subtypes.

As noted above, the subtypes found in our study resemble subtypes that were reported by Critchfield et al. [32] and Lenzenweger et al. [14], probably due to the fact that the clustering procedure was based on similar clustering dimensions. Comparison with other studies is hampered by dissimilarity in the characteristics on which subtypes were formed and described, as well as in the validation measures used. Yet, an externalizing subtype similar to our Extravert/externalizing subtype has been delineated in multiple studies: an angry externalizing and histrionic subtype (both loading heavily on the externalizing dimension) in the adolescent study of by Bradley et al. [29], an externalizing dysregulated subtype in an adult sample [28], and an anxious externalizing subtype [30]. Nearly all previous studies also describe subtypes that in some way resemble our Core BPD and Schizotypal/paranoid subtypes; however, there is considerable variability in terms of how these subtypes are defined and categorized. All these subtypes seem to share an internalizing stance compared with the externalizing subtypes mentioned above. This might suggest that an internalizing-externalizing dimension is important in understanding the heterogeneity of BPD, as has been previously suggested [31, 77].

Importantly, while the subtypes showed distinct features on both the PD comorbidity profiles and relevant concepts such as symptomatic severity, attachment dimensions, identity problems, affective instability, quality of life, 
and interpersonal functioning, differences were small and the subtypes also showed similarities. Interpersonal problems related to a cold/distant and self-centered attitude, attachment avoidance, trauma history of physical abuse, physical neglect and sexual abuse, and personality functioning in terms of social concordance were all domains that showed similarity rather than differentiation between the subtypes. These shared features might be accounted for by the fact that the sample comprised a treatmentseeking population with overall high levels of psychopathology. Correlations between the PD dimensions that remained high in spite of correcting for overall severity indicated the presence of comorbidity that cannot merely be explained by severity in terms of overall personality pathology. A "general p factor" has been identified by Caspi and colleagues [78, 79], which may underlie severe psychopathology and might be responsible for commonalities across the subtypes. On the other hand, Caspi et al. [78] mention an internalizing, externalizing, and thought disorder dimension as accounting for individual differences in symptom picture, although these do not explain harmful dysfunction net of the $\mathrm{p}$ factor. These dimensions might explain the differences that were found in phenotypic expression, aside from the common general psychopathology. Accordingly, two discriminant dimensions were shown to account for the differentiation of the subtypes in this study. The Narcissistic, antisocial, histrionic variate and the Schizotypal variate resemble to some extent the underlying "internalizing/externalizing" and "thought disorder" factors that have repeatedly been demonstrated in studies on the underlying dimensions of psychiatric comorbidity [78, 80, 81].

Future research should extend the current findings by the use of underlying dimensions instead of classification-based data. This might lead to improved understanding of how common-ground dimensional factors such as internalizing/externalizing, thought disorder and overall psychopathology differentiate meaningful subtypes of BPD. This corresponds with the suggestion of Fossati et al. [21] that more meaningful subtypes might be found when taking more dynamic, developmental, dimensional factors into consideration. Future research should also include the notion of differing etiological pathways by examining biomarkers in identified subtypes, as well as including measures that facilitate the identification of working mechanisms. The current findings merely pose a first, though important, step in the possible refinement of therapies and the improvement of treatment outcome, as well as an improved understanding of empirical research on BPD. The results enable researchers to easily categorize patients within the distinct subtypes both within a clinical and research context, based upon their comorbidity profile. The next step would be to start using the identified subtypes in continued research efforts, in order to check for robustness but also to prove their surplus value in research on treatment outcome, trajectories of response, working mechanisms as well as studies on etiology of BPD. Furthermore, as mentioned existing treatment programs are likely tailored for the vast majority and lack specific elements necessary to deal with the characteristics (either full-blown or subthreshold comorbid PD pathology) belonging to the Externalizing and the Schizotypal/paranoid subtype. Future research should take the course of investigating whether or not existing adaptations of evidence based treatment programs [72-74] promote treatment success specifically within these subtypes. At the same time the dearth of treatment programs for these latter two subtypes calls for further innovation of existing treatment programs to tailor to the specific needs of these subtypes. Moreover, to target the Schizotypal/paranoid subtype specifically, there is a challenge in reaching out to these potentially treatment refractory patients, as the results suggest that they may be less inclined to seek help.

Most importantly, the current results raise important questions about the implications of the observed BPD subtypes for research on treatment outcome in terms of (cost-)effectiveness and treatment trajectories, with implications for treatment indication and tailored interventions during treatment. To the best of our knowledge, only Digre et al. [30] have studied subtypes of BPD patients in the context of differential treatment outcome. In that study, three subtypes of BPD patients (withdrawn-internalizing, severely disturbed-internalizing, and anxious-externalizing) were found. The withdrawn-internalizing subtype improved in terms of reduced levels of dissociation, while treatment resolved primarily depressive symptoms in the anxious-externalizing subtype. The severely disturbedinternalizing subtype, which shows some resemblance to both our Core BPD and our Schizotypal/paranoid subtype, did not improve significantly on any outcome measure. A follow-up study will examine treatment trajectories of the subtypes identified in this study in the context of a multi-site trial on the efficacy and costeffectiveness of MBT [2].

Although the study included a relatively large overall sample, its statistical power to find differences was rather limited due to the fact that we allowed the sample sizes of the different subtypes to be unequal in order to amplify the external generalizability of the results based on the idea that the prevalence of distinctive profiles is likely to differ in clinical practice. This resulted in two small clusters and consequently a relative lack of statistical power in comparing the clusters on validation measures. Furthermore, several limitations concerning the characteristics of the present sample dictate caution in interpreting the results of this study. Although 
generalizability was maximized by using few exclusion criteria, generalizability to BPD in general is somewhat doubtful, because the sample included only treatmentseeking patients. In addition, although comorbidity in terms of traits was high, this was not the case in terms of PD diagnosis. Moreover, our sample included mostly female patients, whereas there is no evidence of BPD being more common in women [1]. Although the gender differences between subtypes were profound and some hypotheses explaining this finding have been mentioned above, solid interpretation is hampered by the fact that the distribution of male versus female patients in the overall sample was uneven. Hence, further research is needed to replicate these findings in other samples.

\section{Conclusion}

In sum, this study found three meaningful subtypes that are roughly in line with previous reports and show clinical differences on validation measures. Common underlying factors such as p might account for the similarities, while underlying dimensional constructs also seem to account for the subtype distinction. This parallels the clinical impression that, although they share common features and severity of pathology, patients present with different clinical presentations. The results may be a stepping stone toward research focusing on differential trajectories of change, treatment outcome, and treatment approaches for these distinct subtypes.

\section{Endnotes}

${ }^{1}$ For three patients who did not complete the SCID-I, Axis I diagnoses were based on the diagnosis at intake established by an experienced MSc-level clinical psychologist or psychotherapist.

${ }^{2}$ Correlations between personality dimensions corrected and uncorrected for severity may be obtained from the first author.

${ }^{3}$ Correlations between personality dimensions and canonical discriminant functions are available on request from the first author.

\begin{abstract}
Abbreviations
ANOVA: Univariate analysis of variance; BPD: Borderline personality disorder; BSI: Brief symptom inventory; CTQ: Childhood trauma questionnaire; DSM: Diagnostic and statistical manual of mental disorders; ECR: Experiences in close relationships; EQ: EuroQol; ES: Effect size; IIP: Inventory of interpersonal problems; MANOVA: Multivariate analysis of variance; MBT: Mentalisation-based treatment; PAI-BOR: Personality assessment inventory-borderline; PD: Personality disorder; SCID-I: Structured clinical interview for DSM-IV axis I personality disorders; SCID-II: Structured clinical interview for DSM-IV axis II personality disorders; SD: Standard deviation; SIPP: Severity indices of personality problems; SPSS: Statistical package for the social sciences; VAS: Visual analogue scale
\end{abstract}

\section{Acknowledgements}

We would like to thank all the research assistants for their work in collecting the data and all the patients for taking part in this ongoing study.

\section{Funding}

This study is in part funded by ZonMW, which is the Netherlands Organization for Health Research and Development (grant no. 171202012).

\section{Availability of data and materials}

The datasets used during the current study are available from the corresponding author on reasonable request.

\section{Authors' contributions}

MLS performed the statistical analyses and drafted the first version of the manuscript and maintained the lead in the writing process. PL, RV and $\mathrm{DB}$ co-developed the study design and supervised the project. MLS and DJF were responsible for the coordination of the study and DJF, MLS, JDV, ZW were responsible for collecting the data at the various treatment sites. MLS, DJF, RV and PL made substantial contributions in writing the manuscript. All authors provided comments, read and approved the final manuscript.

\section{Competing interests}

The authors declare that they have no competing interests.

\section{Consent for publication}

Not applicable.

\section{Ethics approval and consent to participate}

This study was approved by the Medical Ethical Committee of Erasmus Medical Center, Rotterdam, The Netherlands (NL38571.078.12). Written informed consent was obtained from all participants after the study had been fully explained.

\section{Publisher's Note}

Springer Nature remains neutral with regard to jurisdictional claims in published maps and institutional affiliations.

\section{Author details}

${ }^{1}$ Viersprong Institute for Studies on Personality Disorders, Halsteren, The Netherlands. ${ }^{2}$ Expertisecentrum MBT-NL, Bergen op Zoom, The Netherlands. ${ }^{3}$ Netherlands Psychoanalytic Institute, Amsterdam, The Netherlands. ${ }^{4}$ Lentis, Groningen, The Netherlands. ${ }^{5}$ Department of Clinical Psychology, University of Amsterdam, Amsterdam, The Netherlands. ${ }^{6}$ Faculty of Psychology and

Educational Sciences, University of Leuven, Leuven, Belgium. ${ }^{7}$ Research

Department of Clinical, Educational and Health Psychology, University

College London, London, UK.

Received: 6 December 2016 Accepted: 8 June 2017

Published online: 03 July 2017

\section{References}

1. Leichsenring F, Leibing E, Kruse J, New AS, Leweke F. Borderline personality disorder. Lancet. 2011;377:74-84.

2. Laurenssen EM, Smits ML, Bales DL, Feenstra DJ, Eeren HV, Noom MJ, et al. Day hospital mentalization-based treatment versus intensive outpatient mentalization-based treatment for patients with severe borderline personality disorder: Protocol of a multicentre randomized clinical trial. BMC Psychiatry. 2014;14:301.

3. Lewis K, Caputi P, Grenyer BFS. Borderline personality disorder subtypes: A factor analysis of the DSM-IV criteria. Personal Ment Health. 2012;6:196-206.

4. McGlashan TH, Grilo CM, Skodol AE, Gunderson JG, Shea MT, Morey LC, et al. The collabarative longitudinal personality disorder study: baseline axis I/II and II/II diagnostic co-occurence. Acta Pssychiatrica Scandinavica. 2000; 102:256-64

5. Yeomans FE, Levy KN, Meehan KB: Treatment approaches for borderline personality disorder. In Psychiatric Times. pp. 42-46; 2012:42-46.

6. Clarkin JF, Yeomans FE, Kernberg OF. Psychotherapy for borderline personality: focusing on object relations. Washington, DC: American Psychiatric Publishing; 2007.

7. Fonagy P, Luyten P. A developmental, mentalization-based approach to the understanding and treatment of borderline personality disorder. Dev Psychopathol. 2009;21:1355-81.

8. Leichsenring F, Rabung S. Long-term psychodynamic psychotherapy in complex mental disorders: update of a meta-analysis. Br J Psychiatry. 2011;199:15-22. 
9. Binks CA, Fenton M, McCarthy L, Lee T, Adams CE, Duggan C. Psychological therapies for people with borderline personality disorder. Cochrane Database Syst Rev. 2006;68

10. Stoffers JM, Vollm BA, Rucker G, Timmer A, Huband N, Lieb K. Psychological therapies for people with borderline personality disorder (Review). Cochrane Database Syst Rev. 2012;8:CD005652.

11. Levy KN. Psychotherapies and lasting change. [Editorial]. Am J Psychiatry. 2008;165:556-9.

12. Leihener F, Wagner A, Haaf B, Schmidt C, Lieb K, Stieglitz R, et al. Subtype differentiation of patients with borderline personality disorder using a circumplex model of interpersonal behavior. J Nerv Ment Dis. 2003;191:248-54.

13. McGorry PD, Hickie IB, Yung AR, Pantelis C, Jackson HJ. Clinical staging of psychiatric disorders: A heuristic framework for choosing earlier, safer and more effective interventions. Aust N Z J Psychiatry. 2006;40:616-22.

14. Lenzenweger MF, Clarkin JF, Yeomans FE, Kernberg OF, Levy KN. Refining the borderline personality disorder phenotype through finite mixture modeling: Implications for classification. J Personal Disord. 2008;22:313-31.

15. Blais MA, Hilsenroth MJ, Castlebury FD. Content validity of the DSM-IV borderline and narcissistic personality disorder criteria sets. Compr Psychiatry. 1997:38:31-7.

16. Clarkin JF, Hull JW, Hurt SW. Factor structure of borderline personality disorder criteria. J Personal Disord. 1993;7:137-43.

17. Sanislow CA, Grilo CM, McGlashan TH. Factor analysis of the DSM-III-R borderline personality disorder criteria in psychiatric inpatients. Am J Psychiatry. 2000;157:1629-33.

18. Hallquist MN, Pilkonis PA. Refining the phenotype of borderline personality disorder: Diagnostic criteria and beyond. Personal Disord. 2012;3:228-46.

19. Clifton A, Pilkonis PA. Evidence for a single latent class of Diagnostic and Statistical Manual of Mental Disorders borderline personality pathology. Compr Psychiatry. 2007:48:70-8.

20. Feske U, Kirisci L, Tarter RE, Pilkonis PA. An application of item response theory to the DSM-III-R criteria for borderline personality disorder. J Personal Disord. 2007:21:418-33.

21. Fossati A, Maffei C, Bagnato M, Donati D, Namia C, Novella L. Latent structure analysis of DSM-IV borderline personality disorder criteria. Compr Psychiatry. 1999;40:72-9.

22. Conway C, Hammen C, Brennan P. A comparison of latent class, latent trait, and factor mixture models of DSM-IV borderline personality disorder criteria in a community setting: implications for DSM-5. J Personal Disord. 2012;26:793-803.

23. Sanislow CA, Grilo CM, Morey LC, Bender DS, Skodol AE, Gunderson JG, et al. Confirmatory factor analysis of DSM-IV criteria for borderline personality disorder: findings from the collaborative longitudinal personality disorders study. Am J Psychiatry. 2002;159:284-90.

24. Trull TJ, Distel MA, Carpenter RW. DSM-5 Borderline personality disorder: At the border between a dimensional and a categorical view. Curr Psychiatry Rep. 2011;13:43-9.

25. Andion O, Ferrer M, Gancedo B, Calvo N, Barral C, Torrubia R, et al. Confirmatory factor analysis of borderline personality disorder symptoms based on two different interviews: the Structured Clinical Interview for DSM-IV Axis II Disorder and the Revised Diagnostic Interview for Borderlines. Psychiatry Res. 2011;190:304-8.

26. Whewell P, Ryman A, Bonanno D, Heather N. Does the ICD 10 classification accurately describe subtypes of borderline personality disorder? $\mathrm{Br} J$ Med Psychol. 2000;73:483-94.

27. Salzer S, Streeck U, Jaeger U, Masuhr O, Warwas J, Leichsenring F, et al. Patterns of interpersonal problems in borderline personality disorder. J Nerv Ment Dis. 2013;201:94-8.

28. Zittel Conklin CZ, Bradley R, Westen D. Affect regulation in borderline personality disorder. J Nerv Ment Dis. 2006;194:69-77.

29. Bradley R, Zittel Conklin C, Westen D. The borderline personality diagnosis in adolescents: gender differences and subtypes. J Child Psychol Psychiatry. 2005;46:1006-19.

30. Digre El, Reece J, Johnson AL, Thomas RA. Treatment response in subtypes of borderline personality disorder. Personal Ment Health. 2009;3:56-67.

31. Kernberg OF, Caligor E. A psychoanalytic theory of personality disorders. In: Lenzenweger MF, Clarkin JF, editors. Major theories of personality disorders. New York: Guilford Press; 2005.

32. Critchfield KL, Clarkin JF, Levy KN, Kernberg OF. Organization of co-occurring Axis II features in borderline personality disorder. Br J Clin Psychol. 2008;47:185-200.
33. First MB, Spitzer RL, Gibbon M, Williams JBW, Benjamin LS. Structured Clinical Interview for DSM-IV Axis II Personality Disorders (SCID II). Washington, DC: American Psychiatric Press; 1996.

34. Weertman A, Arntz A, Kerkhofs MLM. SCID II; gestructureerd klinisch interview voor DSM-IV As-II persoonlijkheidsstoornissen. Amsterdam: Harcourt Test Publishers; 2000.

35. Maffei C, Fossati A, Agostoni I, Barraco A, Bagnato M, Deborah D, et al. Interrater reliability and internal consistency of the Structured Clinical Interview for DSM-IV axis II Personality Disorders (SCID-II), version 2.0. J Personal Disord. 1997;11:279-84.

36. Weertman A, Arntz A, Dreessen L, van Velzen C, Vertommen S. Shortinterval test-retest interrater reliability of the Dutch version of the Structured Clinical Interview for DSM-IV personality disorders (SCID-II). J Personal Disord. 2003;17:562-7.

37. Lobbestael J, Leurgans M, Arntz A. Inter-rater reliability of the Structured Clinical Interview for DSM-IV Axis I Disorders (SCID I) and Axis II Disorders (SCID II). Clin Child Psychol Psychiatry. 2011:18:75-9.

38. First MB, Spitzer RL, Gibbon M, Williams JBW. Structured Clinical Interview for DSM-IV Axis I Disorders (SCID I). Washington DC: American Psychiatric Press; 1997

39. van Groenestijn MAC, Akkerhuis GW, Kupka RW, Schneider N, Nolen WA. Gestructureerd klinisch interview voor de vaststelling van DSM-IV as I stoornissen. Amsterdam: Harcourt Test Publishers; 1999.

40. Ventura J, Liberman RP, Green MF, Shaner A, Mintz J. Training and quality assurance with the Structured Clinical Interview for DSM-IV (SCID-I/P). Psychiatr Res. 1998;79:163-73.

41. Distel MA, De Moor MHM, Boomsma DI. Nederlandse vertaling van de Personality Assessment Inventory-borderline schaal (PAI-BOR): Normgegevens, factorstructuur en betrouwbaarheid. Psychologie en Gezondheid. 2009:37:38-46.

42. Morey LC. The Personality Assesment Inventory: Professional manual. Lutz: Psychological Assesment Resources; 1991.

43. De Beurs E. Brief Symptom Inventory 18, -BSI 18-, Handleiding herziene editie. Leiden: PITS B.V; 2011.

44. Derogatis LR. Brief Symptom Inventory. Baltimore: Clinical Psychometric Research; 1975.

45. Arrindell WA, Ettema JHM. SCL-90-R: Herziene handleiding bij een multidimensionele psychopathologie-indicator. Lisse: Swets \& Zeitlinger; 2003.

46. Derogatis LR. SCL-90: Administration, scoring and procedures manual-I for the r(evised) version. Baltimore: Johns Hopkins University School of Medice, Clinical Psychometrics Research Unit; 1977.

47. Horowitz LM, Alden LE, Wiggins JS, Pincus AL. Inventory of Interpersonal Problems: Manual. San Antonio: Psychological Corporation; 2000.

48. Zevalkink J, de Geus J, Hoek W, Berghout CC, Brouwer D, JMA R-W, et al. Handleiding IIP-64-NL: Inventory of Interpersonal Problems - Nederlandse versie (Manuscript in preparation, version 4.2, June 2012). Amsterdam: Nederland Psychoanalytisch Instituut; 2012.

49. Soldz S, Budman S, Demby A, Merry J. A short form of the Inventory of Interpersonal Problems Circumplex Scales. Assessment. 1995;2:53-63.

50. Brooks R, Rabin R, de Charro F. The measurement and valuation of health status using EQ-5D: A European perspective. London: Kluwer Academic Publishers; 2003.

51. Macran S. Test-retest performance of the EQ-5D. In: Brooks R, Rabin R, de Charro F, editors. The measurement and valuation of health status using EQ-5D: A European perspective. Dordrecht: Kluwer Academic Publishers; 2003. p. 43-54.

52. Verheul R. SIPP-SF: Severity Indices for Personality Problems Short Form. Halsteren: De Viersprong; 2006.

53. Verheul R, Andrea H, Berghout CC, Dolan C, Busschbach JJV, van der Kroft PJA, et al. Severity indices of personality problems (SIPP-118): Development, factor structure, reliability, and validity. Psychol Assess. 2008:20:23-34

54. Brennan KA, Clark CL, Shaver PR. Self-report measurement of adult attachment: an integrative overview. In: Simpsom JA, Rholes WS, editors. Attachment theory and close relationships. New York: The Guilford Press; 1990. p. 46-76.

55. Conradi HJ, Gerlsma C, van Duijn M, de Jonge P. Internal and external validity of the Experiences in Close Relationships questionnaire in an American and two Dutch samples. Eur J Psychiatry. 2006;20:258-69.

56. Bernstein DP, Fink L. Childhood Trauma Questionnaire: A Retrospective Self-report manual. San Antonio: Psychological Corporation; 1998. 
57. Bernstein DP, Stein JA, Newcomb MD, Walker E, Pogge D, Ahluvalia T, et al. Development and validation of a brief screening version of the Childhood Trauma Questionnaire. Child Abuse Negl. 2003;27:169-90.

58. Thombs BD, Bernstein DP, Lobbestael J, Arntz A. A validation study of the Dutch Childhood Trauma Questionnaire-Short Form: factor structure, reliability, and known-groups validity. Child Abuse Negl. 2009:33:518-23.

59. Gore P. Cluster analysis. In: Tinsley H, Browns S, editors. Handbook of applied multivariate statistics and mathametical modeling. San Diego: Academic Press; 2000. p. 297-321.

60. Steinley D, Brusco MJ. Initializing K-means batch clustering: A critical evaluation of several techniques. J Classif. 2007;24:99-121.

61. Breckenridge JN. Validating cluster analysis: consistent replication and symmetry. Multivar Behav Res. 2000;35:261-85.

62. Bozdogan H, Sclove S. Multi-sample cluster analysis using Akaike's Information Criterion. Ann Inst Stat Mathametics. 1984;36:163-80.

63. Schwarz GE. Estimating the dimension of a model. Ann Stat. 1978;6:461-4.

64. Steinley D. K-means clustering: A half-century synthesis. Br J Math Stat Psychol. 2006;59:1-34.

65. Rousseeuw PJ. Silhouettes: A graphical aid to the interpretation and validation of cluster analysis. J Comput Appl Math. 1987;20:53-65.

66. Scholte RHJ, van Lieshout CFM, de Wit CAM, van Aken MAG. Adolescent personality types and subtypes and their psychosocial adjustment. MerrillPalmer Q. 2005;51:258-86.

67. Cohen J. Statistical power analysis for the behavioral sciences. Hillsdale: Lawrence Erlbaum Associates; 1988.

68. Blatt SJ, Auerbach JS. Differential cognitive disturbances in three types of borderline patients. J Personal Disord. 1988;2:198-211.

69. Siever LJ, Torgersen S, Gunderson JG, Livesley WJ, Kendler KS. The borderline diagnosis III: Identifying endophenotypes for genetic studies. Biol Psychiatry. 2002;51:964-8.

70. Weinstein SR, Meehan KB, Cain NM, Ripoll LH, Boussi AR, Papouchis N, et al. Mental state identification, borderline pathology, and the neglected role of childhood trauma. Personal Disord. 2016;7:61-71.

71. Caligor E, Kernberg OF, Clarkin JF. Handbook of dynamic psychotherapy for higher level personality pathology. Washington, DC: American Psychiatric Publishing; 2007.

72. Diamond D, Yeomans FE, Stern B, Levy KN, Horz S, Doering S, et al. Transference focused psychotherapy for patients with comorbid narcissistic and borderline personality disorder. Psychoanal Inq. 2013;33:527-51.

73. Bateman A, Fonagy P. Comorbid antisocial and borderline personality disorders: mentalization-based treatment. J Clin Psychol. 2008;64:181-94.

74. Bernstein DP, Arntz A, de Vos M. Schema focused therapy in forensic settings: Theoretical model and recommendations for best clinical practice. Int J Forensic Mental Health. 2007:6:169-83.

75. Debbané M, Eliez S, Badoud D, Conus P, Fluckiger R, Schultze-Lutter F. Developing psychosis and its risk states through the lens of schizotypy. Schizophr Bull. 2015;41(Suppl 2):S396-407.

76. Badoud D, Billieux J, Eliez S, Imhof A, Heller P. Eytan A, et al. Covariance and specificity in adolescent schizotypal and borderline trait expression. Early Interv Psychiatry. 2015:9:378-87.

77. Caligor E, Clarkin J. An Object Relations model of Personality and Personality Pathology. In: Clarkin J, Fonagy P, Gabberd G, editors. Psychodynamic psychotherapy for personality disorders: A clinical handbook. Washington, DC: American Psychiatric Press; 2010. p. 3-36.

78. Caspi A, Houts RM, Belsky DW, Goldman-Mellor SJ, Harrington H, Israel S, et al. The $\mathrm{p}$ factor: One general psychopathology factor in the structure of psychiatric disorders? Clin Psychol Sci. 2014;2:119-37.

79. Sharp C, Wright AG, Fowler JC, Frueh BC, Allen JG, Oldham J, et al. The structure of personality pathology: Both general (' $g$ ') and specific ('s') factors? J Abnorm Psychol. 2015;124:387-98.

80. Krueger RF, Caspi A, Moffitt TE, Silva PA. The structure and stability of common mental disorders (DSM-III-R): A longitudinal-epidemiological study. J Abnorm Psychol. 1998;107:216-27.

81. Eaton NR, Krueger RF, Keyes KM, Skodol AE, Markon KE, Grant BF, et al. Borderline personality disorder co-morbidity: relationship to the internalizing-externalizing structure of common mental disorders. Psychol Med. 2011;41:1041-50.

\section{Submit your next manuscript to BioMed Central and we will help you at every step:}

- We accept pre-submission inquiries

- Our selector tool helps you to find the most relevant journal

- We provide round the clock customer support

- Convenient online submission

- Thorough peer review

- Inclusion in PubMed and all major indexing services

- Maximum visibility for your research

Submit your manuscript at www.biomedcentral.com/submit
Biomed Central 